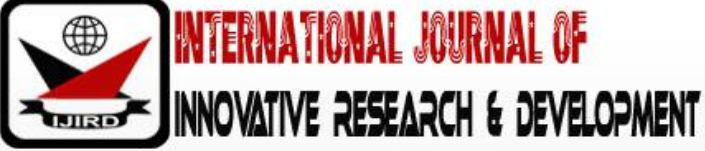

ISSN 2278 - 0211 (Online)

\section{Journaling in Reflective Teaching Approach: An Intervention for Preschool Children's Social Emotional Competences in Molo Sub-County, Kenya}

\author{
Kingaru Thumbi \\ Lecturer, Department of Education, Kenya Methodist University, Kenya \\ Jane Ciumwari Gatumu \\ Associate Professor, Department of Educational Communication and Technology, \\ University of Nairobi, Kenya \\ Dr. Evanson Muriuki Muriithi \\ Lecturer, Department of Educational Communication and Technology, \\ University of Nairobi, Kenya
}

\begin{abstract}
:
This study examines the effect of journaling in reflective teaching approach for preschool children's social emotional competences (SECs) in Molo Sub-county, Kenya from a case of 70 children and 4 teachers in two classes. Methodologies used were; quasi-experimental design with pretest postest model, a training module for preschool teachers, Devereux Student Strengths Assessment(DESSA) pretest and posttest, preschool teachers' semi-structured interview schedule and documentary analysis form for preschool teachers. Teachers in the treatment class were trained on journaling in reflective teaching approach for children's SECs. DESSA was administered in both classes before and after three months on training teacher. The SEC scores were converted to Standard T-score for data analysis using ANCOVA test in SPSS version 21. The study found statistically significant difference in favour of the class where teachers were trained. Semi-structured interview schedule and documentary analysis were also analysed and provided more insights for the study. The findings indicated that journaling in reflective teaching approach could be effective in teaching preschool children's SECs in the Sub-County. This takes place through growth and development of children's social emotional cognitive schema and professionally for teachers. It is recommended that preschool teachers in the Sub-County should be trained in journaling for children's SECs. This should be done through regular in-service courses in journaling, journaling workshops and journaling seminars and, quality maintained through the National and County Governments. Further, Sub-County local resource centers should have scholarly materials on journaling in reflective teaching approach and preschool children's SEC and related literature.
\end{abstract}

Keywords: Journaling, Reflective teaching approach, Preschool Children's Social Emotional Competences

\section{Background}

Preschool education in Kenya is aligned towards positivistic model of teaching and learning, and the fate of children in difficult circumstances is not addressed in the teachers' education and training. The Organization for Economic Cooperation and Development (OECD, 2009) has suggested that the persistence of 'outmoded' transmission models of teaching in global education systems is a barrier to effective learning. In the same context, reflective teaching approach has been advanced as a way out of teachers' predicaments and as a counteraction against the effect of bureaucracy, centralization and control. In this state, teachers are seen solely as deliverers of a fixed curriculum and are not treasured as reflective professionals (Brookfield, 2002). Absence of reflective teaching approach and other alternatives to address children's social emotional competences (SECs) in Molo Sub-County, Kenya made this study worthwhile.

Osterman and Kottkamp (1993) place reflective practice in a constructivist paradigm grounded in (Bruner, 1996) improved theory of constructivism. They term this practice as an experiential learning cycle (Kolb, 1984) consisting of four stages: concrete experience, assessment, re-conceptualization, and testing in new situations. This includes the way teachers think and then write reflectively in journals (Larrivee, 2009).Reflective teaching approach involves an ongoing process of examining and refining practice variously focused on the personal, pedagogical, curricular, intellectual, societal, and/ or ethical contexts associated with teaching and learning (Coles\& Knowles, 2000).One way teachers can be critically reflective is through journaling (Brookfield, 2002; Larrivee, 2009).

According to Larrivee (2009), journaling should be thought and written based on experiential learning cycle. Journaling, as an individual activity, teachers put their thoughts, ideas, feelings and reflections (Gilmore, 1996). After observing what is actually happening in the classroom and school, teachers keep notes in either, dialogue journals, 
learning logs, personal narratives or diaries. These notes include different reflections, which provide them with a critical analysis of what they do in class and help them discover alternative steps to develop reflective practice (Bolton, 2010). Spalding and Wilson (2002) discuss benefits of journaling as serving as a permanent record of thoughts and experiences; serving as a safe outlet for personal concerns and frustrations; and, as an aid to internal dialogue. Hubb and Brand (2005) contends that review of journal entries by teachers encourages personal growth and professional development which means teachers are able to assess the quality of learners' comprehension and mastery of materials as well as learners' effective response to content. The essential goal is to develop self-awareness and have a better perception of teaching/ learning at hand.

According to Moon (1999), the ability to reflect on own and others' emotions, thoughts, and behaviour is the foundation for experiential learning. At the same time, science has established a compelling link between development of children's SECs, behavior and school success (Zins, Blood worth, Weissberg, \& Walberg, 2004). Further, international organisations for example, OECD (OECD, 2015), National governments (Durlak, Domitrovich Weissberg \& Gullota, 2015) and, researchers in prevention science (Seligman, Ernst, Gillham, Reivich\& Linkins, 2009) have recognized that children's SECsare basic requirement for a happy and fulfilling life.

School based prevention programmes have been planned and deployed with encouraging resultsin randomised control trials, indicating long-term positive effects over decades (Durlak et al., 2011).The Perry Program for instance, directed at low-social economic status populations; found that the programme group had6\%of incarceration rates in comparison with $17 \%$ in the control group. The programme group had markedly higher earnings, more stable family relationships, and was healthier 40 years after intervention (Belfield, Nores, Barnett \& Schweinhart, 2006). Failure to adequately cultivate SECs in childhood can lead to mental-health disorders for example, anxiety and dangerous/ risky behaviours such as substance abuse and delinquency (Adi, Killoran, McMillan Kiloran \& Steward-Brown, 2007). In contrast, well-developed children's SECs convey important social outcomes, such as physical health, well-being, academic and work achievements, and civic engagement (Durlak, Weissberg, Dymnicki, Taylor \& Schellinger,2011; OECD, 2015).

Academic reviewers have analysed the evidence base for the effectiveness of social emotional learning programs and found measurable and significant positive effects of social emotional learning in randomised trials. For example, Durlak et al.(2011) report an average of 11\% improvement in academic performance, and 25\% improvement in social and emotional competences. There is indication for positive impacts on many other aspects of behavior for example, improvement inmental health, conflict resolution and reduction in bullying (Adi, et al., 2007; Vreeman \& Carroll, 2007).

According to Durlak et al. (2011) and Wyman et al. (2010) a body of literature in psychology shows that SECs including self-regulation are malleable. There are evidence-based interventions that can change people's ability to self-regulate as well as develop SECs more broadly. In the same context, Moffitt et al. (2011) point out that slight improvement in SECs in early childhood can lead to large positive differences in a person life outcome for both at-risk and general populations with accumulating impacts at the societal level across lifespan. According to Weissberg, Durlak, Domitrovich and Gullotta(2015) one of the most prevalent approach involves training teachers to deliver explicit lessons that teach preschool children's SECs and then finding opportunities for learners to reinforce their use during the course of the day.

The Government of Kenya has not availed pedagogical interventions for preschool teachers in Molo Sub-County whose work occurs in difficult circumstances (Molo Sub-County Education Officer, 2017). At the same time, families with and without children attending preschools have faced social disruptions for more than two and half decades especially; 1992, 1997 and 2007/ 2008 in this region (Koigi, 2009). Although some of the affected families relocated, majority was resettled in the years 2010, 2013, 2014 and 2015 (Molo Sub-County Commissioner, 2017). Social disruptions come along with children lacking basic needs, security needs, self-esteem needs, emotional regulation and attention as is the case of most preschool children in this Sub-County. According to OECD (2006), children who experience social disruptions might have lower than average educational attainment and worse developmental outcomes relative to children in stable families due to delays/ compromised development of academics and social emotional competences.

\subsection{Objective of the Study}

Hypothesizing that there is no significant difference in preschool children's mean scores in SECs between teachers who use journals in reflective teaching approach and those who do not; selected teachers were trained to use journals in reflective teaching approach. This was done in order to determine whether journaling in reflective teaching approach has an effect on preschool children's SECs in the Sub-County.

\subsection{Research Methodology}

Quasi experimental design with pretest-posttest group model was employed on a case of 70 children and 4 teachers in 2 classes in the study. The sample was partitioned into intervention class and a control class. In the intervention class were 33 children and 2 teachers while 37 children and 2 teachers were in the control class. The children were aged between 4 and 6 years. The participating preschools were selected through stratified simple random sampling and simple random sampling from the Sub-County. The intervention class was referred to as journaling class while the class that was not intervened was referred to as the control class. Children's SECs scores were measured in both classes at the beginning of the study using Devereux Student Strengths Assessment (DESSA). These scores were considered as DESSA pretest. Training the teachers on journaling in reflective teaching approach was introduced to the intervention class with monthly follow ups. Three months after the training, children's scores were measured again in both classes. These scores were considered as DESSA posttest. Intervention effect was determined by comparing the DESSA posttest mean score in the intervention class to the mean score in the control class. This was done after subtracting DESSA mean scores obtained at the beginning of the study in both classes using ANCOVA test model(Kothari, 2004). 
Data was collected using at raining module based on Cole \& Knowles, (2000), and Larrivee, (2000) ideas of reflective teaching approach, journaling (Brookfield, 2002; Larrivee, 2009), cyclic nature of reflective teaching (Kolbs, 1984) and importance of children's SECs (Durlak et al., 2011). It was used in teachers' training in the intervention class. The teachers were also trained how to deliver explicit lessons on preschool children's SECs and then to find occasions for learners to strengthen their use throughout the day (Weissberg et al., 2015).This was done after the module was declared valid by a panel of early childhood specialist and piloting in a different preschool in the Sub-County. Teachers attended two days training sessions in plenary and monthly follow ups were made by the researchers.

DESSA a psychometrically sound, norm-referenced and strength-based behavior rating scale was also adopted for this study. It is contains 72-items that yields an overall total score called the social emotional composite. Raw scores obtained are converted to T-score with a mean of 50 and a standard deviation of 10 . The scale is Likert type and range from 0 to 4 representing: never, rarely, occasionally, frequently and very frequently. It contains eight domains that measure SECs: self-awareness, social awareness, self-management, goal directed behavior relationship skills, personal responsibility, responsible decision making and optimistic thinking (LeBuffe, Shapiro\& Naglieri, 2009/2014). The instrument was administered by teachers to preschool children before training and in the last week of the last month of study.

A semi-structured interview schedule was used to gather important information regarding journaling in reflective teaching approach on Children's SECs. Important questions and prompts brought out specific type of responses and enable teachers to extend, elaborate, give details and qualify their answers (Oppenheim, 1992). Piloting established its validity and test-retest reliability found its reliability coefficient at 0.83 . Further, the researchers used documentary analysis for mas indirect technique to facilitate more insights (Burton, 2007). Init were templates to be filled by teachers on what they had documented while journaling on preschool children's SECs. Piloting had established that it had an inter-rater reliability index of 0.81 .

In data analysis, DESSA pretest and DESSA posttest raw scores converted to T-Scores and analysed using Analysis of Covariance (ANCOVA) to test statistical significance difference using Statistical Package for Social Sciences (SPSS) version 21.0 for Windows. In ANCOVA test, the covariate (DESSA pretest) increased power to detect differences between pretest and posttest DESSA scores in both classes. For documentary analysis, a table of presence and absence of records was constructed and average values for the researchers and the independent rater were calculated while data gathered from semi-structured interviews schedules was analysed manually. These two instruments gave more insights on statistical significant difference obtained in both classes.

\section{Finding and Discussions}

Children's mean scores in T-score for journaling and control classes from DESSA pretest and posttest scores were computed to establish which class had improved. The control class had a mean score of 48.378 at pretest and 48.432 at posttest while the journaling class had 47.515 at pretest and 50.524 at posttest. The mean score difference between pretest and posttest was 2.909 and 0.052 for journaling and control classes respectively. The intervention class had a lower mean score at pretest but achieved a higher mean score than control class at posttest. The greater mean score difference for intervention class could be attributed to journaling.

Levels of children's SECs in both classes before and after intervention are shown in Table 1. Also indicated are numbers of children in each level. Children's SECs levels were clustered as follows: Children who scored below 40 T-scores were in need for instructions; those who scored between 41 and 59 T-scores were typical children while those who scored 60 and above T-scores were strengths children (LeBuffe, Shapiro \& Naglieri,2009/2014).

\begin{tabular}{|c|c|c|c|c|}
\hline \multirow{2}{*}{ Level Of Children's Secs } & \multicolumn{2}{|c|}{ Journaling Class } & \multicolumn{2}{c|}{ Control Class } \\
\cline { 2 - 5 } & $\begin{array}{c}\text { Before } \\
\text { treatment }\end{array}$ & $\begin{array}{c}\text { After 3 months } \\
\text { treatment }\end{array}$ & $\begin{array}{c}\text { Before } \\
\text { treatment }\end{array}$ & $\begin{array}{c}\text { After 3 months } \\
\text { treatment }\end{array}$ \\
\hline Need for instructions & 5 & 2 & 3 & 2 \\
Typical & 28 & 29 & 34 & 34 \\
Strengths & 0 & 2 & 0 & 1 \\
Total number of children & 33 & 33 & 37 & 37 \\
\hline
\end{tabular}

Table 1: Children's Scores in SECs before and after 3 Months Intervention for

Journaling and Control classes by Number of Children

Table 1 indicates that 5 children in the journaling class were in need of instructions by scoring below $40 \mathrm{~T}$-scores in the DESSA pretest; of these, 3 transited to the typical level after intervention. Before treatment there were 28 typical children in the class where, 2 transited to strengths level after intervention. There were no strengths in this class before intervention. In the control class, 2 children transited: one from need for instructions level to typical level and another from typical level to strengths level. There were more transitions in the intervention class towards strengths level compared to the control class which could be attributed to journaling.

To determine whether the mean score of the journaling class was statistically different from the control group, an ANCOVA test was carried out. To test the underlying assumption of homogeneity of variance for ANCOVA had been met; a Levene's test of equality of error variance was conducted to test the $H_{0}$ that the error variance of the dependent variable is equal between classes. The error variances are not significantly different, $F(1,68)=0.415 p>0.05$. To find out whether there was interaction between DESSA pretest and the DESSA posttest in both classes, a test of assumption of homogeneity 
of regression slopes was carried. Results indicated that there was no significant interaction of regression slopes, $F(1,66)$ $=0.579, \mathrm{p}>.05$.

To test the effect of journaling on preschool children's SECs while covarying for their SECs before intervention an ANCOVA test was conducted, as shown in Table 2.

\begin{tabular}{|c|c|r|r|r|r|c|}
\hline Source & $\begin{array}{c}\text { Type III Sum } \\
\text { of Squares }\end{array}$ & Df & $\begin{array}{c}\text { Mean } \\
\text { Square }\end{array}$ & \multicolumn{1}{|c|}{ F } & Sig. & $\begin{array}{c}\text { Partial Eta } \\
\text { Squared }\end{array}$ \\
\hline Corrected Model & $1748.244^{\mathrm{a}}$ & 2 & 874.122 & 66.545 & .000 & .665 \\
\hline Intercept & 108.908 & 1 & 108.908 & 8.291 & .005 & .110 \\
\hline Dessapretest & 1679.043 & 1 & 1679.043 & 127.822 & .000 & .656 \\
\hline Group & 126.496 & 1 & 126.496 & 9.630 & .003 & .126 \\
\hline Error & 880.099 & 67 & 13.136 & & & \\
\hline Total & 173256.000 & 70 & & & & \\
\hline Corrected Total & 2628.343 & 69 & & & & \\
\hline
\end{tabular}

Table 2: ANCOVA Analysis for the Effect of Journaling in Reflective Teaching

Approach on Children's SECs Scores

Dependent Variable: Dessaposttest

a. $\mathrm{R}$ Squared $=.665$ (Adjusted R Squared $=.655$ )

According to Table 2, the group source (labeled group on the SPSS output) evaluates whether the means scores of the journaling and the control classes are equal. The results of the analysis indicate that journaling in reflective teaching approach had a significant effect on preschool children's SECs after controlling the effect of teaching SECs without journaling, $F(1,67)=9.630$, $p<.05$, partial $\eta 2=.126$.

To find out if teachers kept journaling records on children's SECs, documents from the intervention and control classes were examined. Table 3 show the average score obtained by the researchers and a trained independent rater. A maximum score of 15.0 indicated intense journaling. The first entry made ascore of1 .0 while the other two items had a maximum score of 5.0 each.

\begin{tabular}{|c|c|c|}
\hline Reflective Journals' Records & Journaling Class Score & Control Class Score \\
\hline A journal & 1.0 & 0.0 \\
\hline Entries on children's SECs & 4.0 & 0.0 \\
\hline $\begin{array}{c}\text { Particular entries on children's social } \\
\text { emotional challenges }\end{array}$ & 3.0 & 0.0 \\
\hline $\begin{array}{c}\text { Score } \\
\text { Maximum score }\end{array}$ & 8.0 & 0.0 \\
\hline
\end{tabular}

Table 3: Analysis of Records Kept by Journaling and Control Classes on Journaling in Reflective Teaching Approach for Children's SECs

Table 3 displays that teachers in the intervention class had a journal, entries on children's SECs and entries on children with social emotional challenges. The journals were well structured with entry templates and sub-entries within the template. The templates were recorded on every weekday. For example, they described significant events that happened in their classes. They also had parts in the template where they interpreted these events in relation to what they thought, felt, knew or realized and then they narrated the outcome of their interpretations. In one of teacher's journal, she had noted that most of children in her class related poorly by forming particular groups and/ or friends while some had no friends. In the interpretation part she had written. Search to find out can be done to have a warmer class, children have friends and groups are friends to each other. On her outcome of her interpretations, she wrote: Arrange partners of my choice and alternate them with children own choices; nurture a climate of kindness, allow more talk time with stories, riddles and dances, observe and teach children how to solve conflicts as well as teach them how to relate with each other by hanging charts and pictures on warmth of friends and groups' friendships.

Along the templates in the journal, she had entries on challenges of teaching children's SECs. She described a problem she had observed in her class: Children with serious social emotional challenges- do not get along with others and some use improper language, some do not calm down easily. On the outcome of her interpretation part, she wrote: Spend one-on-one time with children in order to build trust, suggest friends for children as well as hear their own suggestions; tell them in advance of the consequences of using improper language, cerebrate their new friends and good behaviour. The journaling class had a mean score of $8.0(72.72 \%)$ to a maximum of 11.0 compared to teachers in the control class who had none of the documents under investigation with a mean score of $0.0 \mathrm{a}$ maximum score of 11.0. Presence of these documents and required entries in the intervention class indicated actual journaling in reflective teaching approach.

Preschool teachers' interviews were conducted after DESSA posttest in both classes. Teachers in the intervention class stated that they taught SECs through explicit lesson and found opportunities for children to strengthen their use in the course of the day. They said that children appeared to improve in these competences when they employed journaling as opposed to ordinary methods where they relied on memory. They had a positive attitude towards journaling (as compared to routine writing) which they stated facilitated them to keep track of children's SECs and their own teaching. They also 
stated that journaling facilitated them to reflect and follow up children's SECs as pointed out by Larrivee (2009) that journaling promote reflective teaching that lead to more effective teaching.

Teachers in the treatment class also said that journal reviews assisted them to search for solutions when faced with problems on children's SECs. Further, they stated that journal reviews assisted them (teachers) to learn as as found out by Hubb and brand (2005) that journal' sentries encourage personal growth and professional development. Though these reviews, the teachers were able to assess the quality of learners' comprehension and mastery of SECs as well as children's effective response to SECs. They said that on reviewing their journals, they were able to recall and follow up various features of SECs for example; optimistic thinking, personal responsibility, goal directed behavior among others and hence foster them in their classes.

Teachers in the control class were weak at journaling in reflective teaching approach. They did not seem to keep track of teaching and learning on children's SECs using journals or any other form of writing apart from memory. A teacher stated I do not record how I teach and how children learn SECs in a journal. I have not been trained how to use a journal to teach. These could explain the lower mean scores obtained by this class which was significantly different from the treatment class. According to teachers in the treatment class, through journaling children's SECs improved and this was confirmed by the superior scores in this class as compared to the control class. For this reason, this study is in agreement what has been studied by scholars and researchers in reflective teaching approach, journaling and children's SECs (Coles\& Knowles, 2000;Larrivee, 2009;Moon, 1999; Weissberg et al.,2015) and a point out that journaling in reflective teaching approach could be effective in teaching preschool children's SECs in the Sub-County.

\section{Conclusions and recommendations}

This paper point at the effectiveness of journaling in reflective teaching approach intersected with preschool children's SECs. The findings show that journaling can boost significantly children's SECs through construction of cognitive structures to which these competences are rooted. The teachers can also develop professionally by being accurately aware of their practice. These occur when SECs are taught through explicit lessons and occasions found for children to strengthen their use in the course of the day. Children develop, comprehend and retain these competences better when taught by critically reflective teachers during in and out of class hours.

Preschool teachers in the Sub-County and similar localities should be trained in journaling in reflective teaching approach for preschool children's SECs. This should be done through regular in-service courses on journaling, journaling workshops and journaling seminars and quality maintained in preschool through the National, Nakuru County Governments. Local resource centers for preschool teachers in the Sub-County should have scholarly literature for journaling in reflective teaching approach and preschool children's SECs and, related literature.

\section{References}

i. Adi, Y., McMillan, A., Killoran, A.,\& Stewart-Brown, S. (2007b). Systematic review of the effectiveness of interventions to promote mental well-being in primary schools: Universal approaches which focus on prevention of violence and bullying. London: National Institute for Clinical Excellence.

ii. Belfield, C. R., Nores, M., Barnett, S.,\& Schweinhart, L. (2006). The high/ scope Perry preschool program: Cost benefit analysis using data from the age-40 follow up. J. Human Resources, 41(1), 162-190.doi: 10.3368/ jhr.XLI.1.162

iii. Bolton, G. (2010). Reflective practice: Writing and professional development. London: Sage.

iv. Brookfield, S. D. (2002). Using the lenses of critically reflective teaching in the community college classroom. New York: Wiley Periodical Inc.

v. Bruner, J. (1996). The culture of education. Cambridge, MA: Harvard university press.

vi. Burton, N. (2007). The research process. In P. Zwozdiak-Myers (Ed.). Childhood and youth students: Learning matters. Oxford: Blackwell.

vii. Coles, A. L., \&Knowles, J. G. (2000). Researching teaching: Exploring teacher development through reflexive inquiry. Boston : Allyn and Bacon.

viii. Durlak, J.A., Domitrovich,C. E., Weissberg,R. P., \& Gullota,T. P. (2015). Handbook of social and emotional learning: Research and practice. New York: Guilford Publications.

ix. Durlak, J.A., Weissberg,R. P., Dymnicki,A. B., Taylor,R. D.,\& Schellinger, K. B.(2011).The impact of enhancing students' social and emotional learning: A meta-analysis of school-based universal interventions. Child Development, 82(1), 405-432. doi: 10.1111/j.1467-8624.2010.01564.x.

x. Gilmore, F. (1996). Qualitative research: Written journals within teacher training (Unpublished manuscript). Christchurch College of Education, Christchurch New Zealand.

xi. Hubb, L. D.\& Brand, F. C. (2005). The paper mirror: Understanding reflection. Journal of Experiential Education,28(1), 60-77. doi.org/ 10.1177/ 105382590502800107

xii. Larrivee, B. (2009). Authentic classroom management: Creating a learning community and building reflective practice(3rdEd.). Upper Saddle River, NJ: Pearson.

xiii. LeBuffe, P. A., Shapiro , V. B. , \& Naglieri, J. A . (2009/ 2014). The Devereux Student

xiv. Strengths Assessment (DESSA): Assessment, technical manual, and user's guide . Charlotte , NC: Apperson , Inc

xv. Koigi, W. (2009). Towards genocide in Kenya. Nairobi: Spear Books.

xvi. Kolb, D. A. (1984). Experiential learning: Experience as the source of learning and development. New Jersey: Prentice Hall.

xvii. Kothari, C. R. (2004). Research Methodology (Rev Ed.). Delhi: New Age International. 
xviii. Moffitt,T. E., Arseneault, L., Belsky, D., Dickson,N., Hancox,R. J., Harrington,H.,\&Houts, R. (2011). Gradient of childhood self-control predicts health, wealth, and public safety. Proceedings of the National Academy of Sciences, 108(7), 2693-2698.doi: 10.1073/ pnas.1010076108

xix. Moon, J. (1999). Reflective in learning and professional development theory and practice. London: Kogan Page.

xx. Molo Sub-County Commissioner. (2017, October 18). Personalinter view.

xxi. Molo Sub-County Education Officer. (2017, November 1). Personal interview.

xxii. Oppenheim, A. (1992). Questionnaire design, interview and attitude measurement. London: Cassell.

xxiii. Organization of Economic Cooperation and Development (OECD). (2015).Skills for Social Progress, Technical Report. OECD.

xxiv. Organization of Economic Cooperation and Development (OECD). (2009). Creating effective teaching and learning environments: First results from TALIS. Retrieved from http:/ / www.oecd.org/ edu/ school/ 43023606.pdf

xxv. Organisation for Economic Cooperation and Development (OECD). (2006). Starting Strong II, Annex E. Paris, France: OECD.

xxvi. Osterman, K. F., \& Kottkamp.R. B. (2004). Reflective practice for education. California: Corwin Press.

xxvii. Seligman,M. E. P., Ernst,R., Gillham,M. J., Reivich,J. K.,\& Linkins, M.(2009). Positive education: Positive psychology and classroom interventions.Oxford Review of Education, 35 (3), 293-311. doi: 10.1080/ 03054980902934563

xxviii. Spalding, E.,\& Wilson, A. (2002). Demystifying reflection: A study of pedagogical strategies that encourage reflective journal writing.Teachers College Record, 104(4), 1393-1421.

xxix. Vreeman R. C.,\& Carroll, A. E. (2007). A systematic reviews of school-based interventions to prevent bullying.American Medical Association, 161(1), 78-88.

xxx. Weissberg R., Durlak J., Domitrovich, C.,\& Gullotta, T. (2015). Social and emotional learning: past, present, and future, in Handbook of Social and Emotional Learning (Eds.). Durlak J., Domitrovich C., Weissberg R., Gullotta T.New York, NY: The Guilford Press.

xxxi. Wyman, P.A., Braun, C.H., Lomurray, M., Schmeelk-cone, M., Petrovam, M., Yu, Q.,\& Wang, W. (2010). An outcome evaluation of the sources of strength suicide prevention program delivered by adolescent peer leaders in high schools. American Journal of Public Health, 100(9), 1653-166. doi:10.2105/ AJPH.2009.190025

xxxii. Zins, J.E., Weissberg, R.P., Wang, M.C.,\& Walberg, H. J. (2004). Building academic success through social and emotional learning: What does the research say? New York: Teachers College Press. 